\title{
Investigation the Cognitive Impairment in Diabetes Mellitus Type 2 with Moca Test
}

\section{Tuba Özcan ${ }^{1 *}$ and Esra Yancar Demir ${ }^{2}$}

${ }^{1}$ Ordu University, School of Medicine, Department of Neurology, Ordu/ Turkey

${ }^{2}$ Ordu University, School of Medicine, Department of Psychiatry, Ordu/ Turkey

*Corresponding author: Tuba Özcan, Ordu Üniversitesi, Tıp Fakültesi, Nöroloji AD, Ordu/Turkey; Tel: 90533 4796529; E-mail: dr_aydemir@yahoo.com

Received Date: July 1, 2014, Accepted Date: September 26, 2014, Published Date: October 3, 2014

Copyright: (c) 2014, Özcan and Demir. This is an open-access article distributed under the terms of the Creative Commons Attribution License, which permits unrestricted use, distribution, and reproduction in any medium, provided the original author and source are credited.

\begin{abstract}
Objective: Type 2 diabetes mellitus (DM) is one of the most common major diseases in older adults, and its prevalence increases with age. DM not only causes somatic complications but also may lead to cognitive dysfunction. The aim of this investigation is to reveal the relationship between diabetes mellitus type 2 and cognitive impairment $(\mathrm{Cl})$.

Method: Over a 6-month period, a total of 15 DM (12 male and 3 female) and, 15 non- DM (12 male and 3 female) subjects were included the study. Each DM patient was matched when possible with a non- DM control subject. Information collected from other hospital records and medical notes. The Montreal Cognitive Assessment (MoCA) is a screening instrument for $\mathrm{Cl}$.

Results: Mean age of the study subjects was $69.9 \pm 7.43$ years and $6(20 \%)$ of the study subjects were females. The prevalence of $\mathrm{Cl}$ was $83.3 \%(25 / 30)$ in the whole group and $73.3 \%(11 / 15)$ in patients with DM, whereas it was $93.3 \%(14 / 15)$ in non- DM group. The mean scores were $15.53 \pm 6.18$ and $15.40 \pm 3.99$, respectively ( $p$ : 0.945 ). There was no significant difference between diabetic and non-diabetic groups in terms of MoCA domains.

Discussion: Compared with an age- and gender-matched group of non-diabetic control subjects, this study demonstrated that no differences of prevalence for $\mathrm{Cl}$ in an elderly group of patients with $\mathrm{DM}$. $\mathrm{Cl}$ prevalence in our study, in both DM (73.3\%) and non-DM groups $(93.3 \%)$ is much higher than the literature and it makes us to think that MoCA test is not appropriate for our population.

Conclusion: According to our findings, $\mathrm{Cl}$ was similar in both groups and prevalence was not different between groups. Furhter studies with longitudinal designs are needed to identify the relationship between $\mathrm{DM}$ and $\mathrm{Cl}$.
\end{abstract}

Keywords: Diabetes Mellitus; Cognitive impairment; MoCA test

\section{Introduction}

Type 2 diabetes mellitus (DM) is one of the most common major diseases in older adults, and its prevalence increases with age $[1,2]$. Patients with DM are subjected to micro angiopathic complications as neuropathy, retinopathy, nephropathy and macro angiopathic atherosclerosis as stroke and ischemic heart disease. DM not only causes somatic complications but also may lead to cognitive dysfunction [3-8]. Several hypotheses have been suggested for a relationship between DM and cognitive impairment (CI). One of them is DM has an indirect effect on cognition via vascular disease [9]. It was reported that elderly DM patients have impaired cognition in comparison to age- matched controls [10,11]. Although cognitive dysfunction has been reported in patients with DM, there is not any specific domains of cognition that may be related by DM $[3,12,13]$.

The aim of this investigation is to reveal the relationship between diabetes mellitus type 2 and cognitive impairment.

\section{Material and Methods}

This retrospective study was performed in Ordu University. After the study protocol was approved by the local ethical committee, over a 6-month period, a total of $15 \mathrm{DM}$ (12 male and 3 female) and, 15 nonDM (12 male and 3 female) subjects were included the study. Each DM patient was matched when possible with a non- DM control subject, of the same gender and whose age was within 2 years of that of the patient. None of the control subject had a history of DM and had not been prescribed oral hypoglycaemic agents or insulin. All patients were aged 60 years or more. Information collected from other hospital records and medical notes.

The Montreal Cognitive Assessment (MoCA) is a screening instrument for CI, but MoCA has not been validated in patients with DM. The MoCA consists of 7 subscores: visuospatial/executive (5 points); naming (3 points); memory (5 points for delayed recall); attention ( 6 points); language ( 3 points); abstraction ( 2 points); and orientation ( 6 points) and upper score limit is 30 . One point is added if the subject has 12 years of education. The cut-off value is determined as $21[14,15]$.

Statistical analyses were performed using the Statistical Package for the Social Sciences (SPSS), Version 20. Descriptive statistics were used to summarize all measurements. All continuous data mean \pm standard 
deviation. The Mann-Whitney $U$ test and chi-square test was used for statistical comparisons. The level of statistical significance was set as $\mathrm{p}<0.05$.

\section{Results}

Mean age of the study subjects was $69.9 \pm 7.43$ years and $6(20 \%)$ of the study subjects were females. Statistical analysis did not show significant difference between education level of two groups (p: 0.824). The frequency of CI was $83.3 \%$ (25/30) in the whole group and $73.3 \%$ $(11 / 15)$ in patients with DM, whereas it was $93.3 \%(14 / 15)$ in non- DM group. The mean scores were $15.53 \pm 6.18$ and $15.40 \pm 3.99$, respectively ( $\mathrm{p}$ : 0.945). Characteristics of diabetic and non-diabetic group are shown in Table 1 . There was no significant difference between diabetic and non-diabetic groups in terms of MoCA domains Table 2.

\begin{tabular}{|c|c|c|c|}
\hline & DM & Non-DM & $\mathbf{p}$ \\
\hline Gender $(M / F)$ & $12 / 3$ & $12 / 3$ & 1 \\
\hline Age & $71.27 \pm 8.57$ & $69.20 \pm 5.06$ & 0.428 \\
\hline Education state & \multirow[t]{2}{*}{0} & \multirow[t]{2}{*}{1} & \multirow[t]{2}{*}{0.824} \\
\hline none & & & \\
\hline literate & 4 & 5 & \\
\hline elementary school & 8 & 7 & \\
\hline middle school & 1 & 1 & \\
\hline high school & 1 & 0 & \\
\hline college & 1 & 1 & \\
\hline $\mathrm{Cl}$ & 11 & 14 & 0.142 \\
\hline MoCA Score & $15.53 \pm 6.18$ & $15.40 \pm 3.99$ & 0.945 \\
\hline
\end{tabular}

Table 1: Characteristics of diabetic and non-diabetic group and comparison of cognitive state in both.

\begin{tabular}{|l|l|l|l|}
\hline MoCA domain & DM & Non-DM & $\mathbf{p}$ \\
\hline Visuospatial /Executive & $1.80 \pm 1.17$ & $1.80 \pm 1.56$ & 1 \\
\hline Attention & $3.40 \pm 2.02$ & $2.60 \pm 1.50$ & 0.230 \\
\hline Language & $1.33 \pm 0.82$ & $1.33 \pm 0.82$ & 0.512 \\
\hline Abstraction & $1.27 \pm 0.79$ & $0.86 \pm 0.80$ & 0.135 \\
\hline Delayed recall & $1.60 \pm 1.08$ & $1.31 \pm 1.1$ & 0.387 \\
\hline Orientation & $4.87 \pm 1.46$ & $5.13 \pm 1.19$ & 0.587 \\
\hline
\end{tabular}

Table 2: Scores and comparison of MoCA domains of diabetic and non-diabetic group.

\section{Discussion}

In the present study, we investigated factors associated with CI in elderly DM subjects using MoCA. Compared with an age- and gendermatched group of non-diabetic control subjects, this study demonstrated that no differences of frequency for CI in an elderly group of patients with DM.

In previous studies, controversial results have been stated for the DM as a risk for CI. Although some of the studies have found a relationship between DM and CI, others have reported no relationship $[4-8,16]$. Katzman et al. found an association between DM and dementia [17]. Contrary, in a cross-sectional study conducted by Croxson et al. did not find a significant difference [18]. In another study, authors concluded that, borderline diabetes increases risks of dementia [19]. In our study, regardless of a small number of participants and a different method and scale in determination of CI, we did not found a different frequency of $\mathrm{CI}$ in diabetic group.

Prevalence of CI in DM ranging from $20 \%$ to $38 \%$ [20-22]. In a population-based study, CI in patients with DM was reported as $28 \%$ [20]. CI frequency in our study, in both DM (73.3\%) and non-DM groups $(93.3 \%)$ is much higher than the literature and it makes us to think that MoCA test is not appropriate for our population or we have made mistakes in patient selection. It should be related to lower educational state of our patients and the absence of the MoCA test form for untrained people. Also, cause of retrospective design of the study, none of the control subject's brain imaging was evaluated. So, we cannot say that our control group was entirely healthy people. On the other hand, other etiological factors might be interacted to our results. We did not, therefore, examine all possible factors which may have effect on CI. We also did not specifically examine the unrecognized depression or DM and medication. Moreover, we did not question the past history of intellectual ability, which may have implications for evaluating the cognition.

Main limitation of our study is small sample size. The other limitations of our study are not excluding the metabolic and the structural conditions were not excluded. Maybe, we should have investigated the routine blood tests and neuroimaging to find the other causes of CI.

In the present study we evaluated the effect of DM on CI. We compared frequency of CI in diabetic and non-diabetic group, matched in age, sex and educational state. According to our findings, CI was similar in both groups and frequency was not different between groups. Furhter studies with longitudinal designs are needed to identify the relationship between DM and CI.

\section{References}

1. Wild S, Roglic G, Green A, Sicree R, King H (2004) Global prevalence of diabetes: estimates for the year 2000 and projections for 2030. Diabetes Care 27: 1047-1053.

2. Zimmet P, Alberti KG, Shaw J (2001) Global and societal implications of the diabetes epidemic. Nature 414: 782-787.

3. Logroscino G, Kang JH, Grodstein F (2004) Prospective study of type 2 diabetes and cognitive decline in women aged 70-81 years. BMJ 328: 548.

4. Ebady SA, Arami MA, Shafigh MH (2008) Investigation on the relationship between diabetes mellitus type 2 and cognitive impairment. Diabetes Res Clin Pract 82: 305-309.

5. Umegaki H, Iimuro S, Kaneko T, Araki A, Sakurai T, et al. (2008) Factors associated with lower Mini Mental State Examination scores in elderly Japanese diabetes mellitus patients. Neurobiol Aging 29: 1022-1026.

6. Ruis C1, Biessels GJ, Gorter KJ, van den Donk M, Kappelle LJ, et al. (2009) Cognition in the early stage of type 2 diabetes. Diabetes Care 32: 1261-1265.

7. Luchsinger JA (2012) Type 2 diabetes and cognitive impairment: linking mechanisms. J Alzheimers Dis 30 Suppl 2: S185-198. 
Citation: Özcan T, Demir EY (2014) Investigation the Cognitive Impairment in Diabetes Mellitus Type 2 with Moca Test. J Psychiatry 17: 1000166. doi:10.4172/Psychiatry.1000166

Page 3 of 3

8. Luchsinger JA, Palmas W, Teresi JA, Silver S, Kong J, et al. (2011) Improved diabetes control in the elderly delays global cognitive decline. J Nutr Health Aging 15: 445-449.

9. Legato MJ, Gelzer A, Goland R, Ebner SA, Rajan S, et al. (2006) Genderspecific care of the patient with diabetes: review and recommendations. Gend Med 3: 131-158.

10. Cukierman T, Gerstein HC, Williamson JD (2005) Cognitive decline and dementia in diabetes--systematic overview of prospective observational studies. Diabetologia 48: 2460-2469.

11. Strachan MW, Deary IJ, Ewing FM, Frier BM (1997) Is type II diabetes associated with an increased risk of cognitive dysfunction? A critical review of published studies. Diabetes Care 20: 438-445.

12. Kalmijn S, Feskens EJ, Launer LJ, Stijnen T, Kromhout D (1995) Glucose intolerance, hyperinsulinaemia and cognitive function in a general population of elderly men. Diabetologia 38: 1096-1102.

13. Saczynski JS, Jónsdóttir MK, Garcia ME, Jonsson PV, Peila R, et al. (2008) Cognitive impairment: an increasingly important complication of type 2 diabetes: the age, gene/environment susceptibility--Reykjavik study. Am J Epidemiol 168: 1132-1139.

14. Selekler K, Cangöz B, Uluç S (2010) Montreal Bilissel Degerlendirme Ölçegi (MOBID)'nin hafif bilissel bozukluk ve Alzheimer hastalarini ayirt edebilme gücünün incelenmesi. Turkish Journal of Geriatrics 13: 166-171.

15. Nasreddine ZS, Phillips NA, Bédirian V, Charbonneau S, Whitehead V, et al. (2005) The Montreal Cognitive Assessment, MoCA: a brief screening tool for mild cognitive impairment. J Am Geriatr Soc 53: 695-699.

16. Hassing LB, Hofer SM, Nilsson SE, Berg S, Pedersen NL, et al. (2004) Comorbid type 2 diabetes mellitus and hypertension exacerbates cognitive decline: evidence from a longitudinal study. Age Ageing 33: 355-361.

17. Katzman R, Aronson M, Fuld P, Kawas C, Brown T, et al. (1989) Development of dementing illnesses in an 80-year-old volunteer cohort. Ann Neurol 25: 317-324.

18. Croxson SC, Jagger C (1995) Diabetes and cognitive impairment: a community-based study of elderly subjects. Age Ageing 24: 421-424.

19. Xu W1, Qiu C, Winblad B, Fratiglioni L (2007) The effect of borderline diabetes on the risk of dementia and Alzheimer's disease. Diabetes 56: 211-216.

20. Luchsinger JA, Reitz C, Patel B, Tang MX, Manly JJ, et al. (2007) Relation of diabetes to mild cognitive impairment. Arch Neurol 64: 570-575.

21. van den Berg E, Kessels RP, de Haan EH, Kappelle LJ, Biessels GJ (2005) Mild impairments in cognition in patients with type 2 diabetes mellitus: the use of the concepts MCI and CIND. J Neurol Neurosurg Psychiatry 76: 1466-1467.

22. Yamazaki Y, Miwa T, Sakurai H, Hanyu H, Iwamoto T, et al. (2011) Clinical backgrounds and morbidity of cognitive impairment in elderly diabetic patients. Endocr J 58: 109-115. 